\title{
Características nutricionais da carne de cordeiros terminados com dietas contendo cana-de-açúcar ou silagem de milho e dois níveis de concentrado ${ }^{1}$
}

\author{
André Gustavo Leão², Américo Garcia da Silva Sobrinho3 ${ }^{3}$, Greicy Mitzi Bezerra Moreno², \\ Hirasilva Borba Alves de Souza ${ }^{3}$, Henrique Leal Perez ${ }^{2}$, Cíntia Maria Battiston Loureiro ${ }^{2}$
}

\footnotetext{
1 Pesquisa financiada pela FAPESP.

2 Pós-Graduação em Zootecnia - FCAV/Unesp - Jaboticabal/SP.

${ }^{3}$ FCAV/Unesp - Jaboticabal/SP.
}

RESUMO - Com o objetivo de avaliar as características nutricionais da carne de cordeiros terminados em confinamento com dietas contendo cana-de-açúcar ou silagem de milho em duas relações volumoso:concentrado (60:40 ou 40:60), utilizaram-se 32 cordeiros Ile de France, não-castrados, com $15 \mathrm{~kg}$ de peso corporal distribuídos em delineamento experimental inteiramente casualizado, em esquema fatorial $2 \times 2$. Os animais foram confinados em baias individuais e abatidos aos $32 \mathrm{~kg}$. A carne dos cordeiros teve 74,55\% de umidade, 19,61\% de proteína bruta, 1,04\% de cinzas e 51,28 mg/100 g de colesterol. O teor de extrato etéreo foi maior na carne dos cordeiros alimentados com dietas com silagem de milho (3,97\%) e na carne daqueles que receberam alimentação mais concentrada (4,02\%). Os ácidos graxos em maior concentração na carne

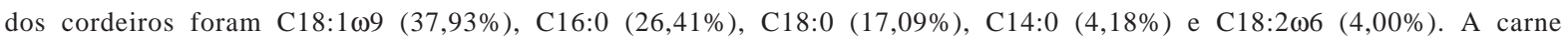

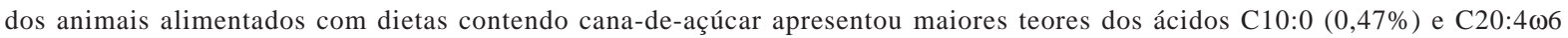

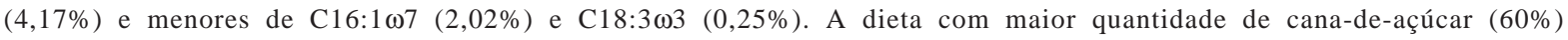
promoveu maiores teores dos ácidos C15:0 (0,68\%), C17:0 (2,13\%) e C20:2 (1,34\%) na carne. Dietas contendo cana-deaçúcar ou maior quantidade de volumoso (60\%) promovem menor deposição de gordura na carne de cordeiros. O tipo de volumoso tem maior influência no perfil de ácidos graxos da carne de cordeiro em comparação à relação volumoso:concentrado das dietas. Dietas contendo cana-de-açúcar em maiores proporções originam carne com maiores concentrações de ácidos graxos saturados de cadeia ímpar.

Palavras-chave: ácidos graxos, carne ovina, colesterol, composição centesimal, confinamento, relação volumoso:concentrado

\section{Nutritional characteristics of meat from lambs finished with diets containing sugar cane or corn silage on two levels of concentrate}

\footnotetext{
ABSTRACT - The objective of this work was to evaluate nutritional characteristics of meat from lambs finished on feedlot with diets containing sugar cane or corn silage on two roughage:concentrate ratios (60:40 or 40:60). It was used 32 non castrated Ile de France lambs, with $15 \mathrm{~kg}$ of body weight distributed in a complete random experimental design in a $2 \times 2$ factorial arrangement. The animals were confined in individual stalls and slaughtered at $32 \mathrm{~kg}$. Lamb meats had $74.55 \%$ of moisture, $19.61 \%$ of crude protein, $1.04 \%$ of ash and $51.28 \mathrm{mg} / 100 \mathrm{~g}$ of cholesterol. Ether extract was greater in meat of lambs fed corn silage (3.97\%) and in the meat of those animals which received more concentrate food (4.02\%). Fatty acids at greater concentration in lamb meat were: C18:109 (37.93\%), C16:0 (26.41\%), C18:0 (17.09\%), C14:0 (4.18\%)

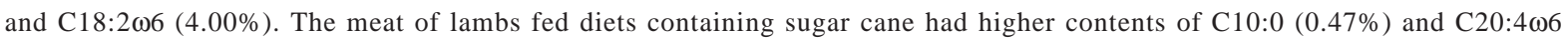
(4.17\%), and lower contents of $\mathrm{C} 16: 1 \omega 7(2.02 \%)$ and $\mathrm{C} 18: 3 \omega 3$ (0.25\%). Diet with greater amount of sugar cane (60\%) promoted more contents of acids C15:0 (0.68\%), C17:0 (2.13\%) and C20:2 (1.34\%) in the meat. Diets with sugar cane or more quantities of roughage (60\%) promote lower deposition of fat in lamb meat. Type of roughage has more influence on fatty acid profile of lamb meat when compared to roughage:concentrate ratio of diets. Diets containing higher quantity of sugar cane originate lamb meat with greater concentrations of odd chain saturated fatty acids.
}

Key Words: centesimal composition, cholesterol, fatty acids, feedlot, roughage:concentrate ratio, sheep meat 


\section{Introdução}

Atualmente, tem-se discutido muito a relação nutrição humana e saúde, frente aos problemas relacionados à ingestão de determinados alimentos (Costa et al., 2008; Nuernberg et al., 2008; Vandendriessche, 2008; McAfee et al., 2010). Quando se almeja qualidade de vida e adoção de atitudes compatíveis com a prevenção de doenças, é cada vez maior o interesse da população em saber o que se consome (Scollan et al., 2006), inclusive os parâmetros nutricionais desejáveis dos alimentos, o teor de gordura da carne e sua composição em ácidos graxos.

A carne ovina contém aproximadamente 4\% de gordura (Prata, 1999), e é rica em ácidos graxos saturados e monoinsaturados, com menores quantidades de poliinsaturados (Monteiro et al., 2007). Os ácidos saturados mais encontrados nesta carne são o mirístico (C14:0), palmítico (C16:0) e esteárico (C18:0); os monoinsaturados palmitoleico (C16:1 $\omega 7)$ e oleico $(\mathrm{C} 18: 1 \omega 9)$ e os poliinsaturados linoleico (C18:2 $\omega 6$ ), linolênico (C18:3 $\omega 3$ ) e araquidônico (C20:4 $\omega 6$ ).

A carne dos ruminantes, quando comparada à dos monogástricos, possui maior concentração de ácidos graxos saturados e menor relação poliinsaturados:saturados, e essa grande diferença é resultado do processo de biohidrogenação dos ácidos graxos insaturados pela ação de microrganismos ruminais (French et al., 2000).

Vale salientar que vários fatores podem afetar o processo de biohidrogenação e a composição dos ácidos graxos depositados na carne, bem como seu teor de colesterol. Entre esses fatores, destacam-se o sistema de alimentação, a composição das dietas, a relação volumoso:concentrado e o tipo de volumoso utilizado (Demirel et al., 2006; Nuernberg et al., 2008).

Considerando a escassez de trabalhos com cana-deaçúcar in natura na alimentação de ovinos e a elevada exigência do mercado consumidor em relação às características qualitativas da carne, são necessárias informações da influência dessa fonte volumosa, associada a alimentos concentrados, em relação às características nutricionais da carne ovina. Assim, objetivou-se avaliar o efeito de dietas com maior ou menor teor de concentrado, associado à cana-de-açúcar ou silagem de milho, na composição centesimal, teor de colesterol e perfil de ácidos graxos da carne de cordeiros terminados em confinamento.

\section{Material e Métodos}

O experimento foi desenvolvido na Faculdade de Ciências Agrárias e Veterinárias da Universidade Estadual
Paulista (FCAV/Unesp), Campus de Jaboticabal, São Paulo, localizada a $21^{\circ} 15^{\prime} 22^{\prime \prime}$ de latitude Sul e $48^{\circ} 18^{\prime} 58^{\prime \prime}$ de longitude Oeste, com altitude de $595 \mathrm{~m}$. A fase de campo foi realizada no Setor de Ovinocultura, e as análises laboratoriais no Laboratório de Tecnologia dos Produtos de Origem Animal, pertencentes a esta Instituição Universitária.

Foram utilizados 32 cordeiros Ile de France, machos não castrados, com peso corporal inicial de $15 \mathrm{~kg}$. Os animais foram identificados com marcação numérica na região lombar, everminados e receberam suplementação de vitaminas A, D e E. Posteriormente, foram confinados em baias individuais, equipadas com comedouros e bebedouros e dispostas em área coberta.

Os cordeiros foram distribuídos em quatro tratamentos, constituídos por dietas com duas relações volumoso:concentrado (60:40 e 40:60) e dois volumosos (silagem de milho e cana-de-açúcar), sendo: 60\% de silagem de milho $+40 \%$ de concentrado; $60 \%$ de cana-de-açúcar + $40 \%$ de concentrado; $40 \%$ de silagem de milho $+60 \%$ de concentrado e $40 \%$ de cana-de-açúcar $+60 \%$ de concentrado.

A cana-de-açúcar utilizada no experimento foi a IAC 86-2480, variedade desenvolvida pelo Instituto Agronômico de Campinas (IAC) para alimentação animal. A cana-deaçúcar (primeiro corte) pertencia ao canavial experimental da FCAV, formado no ano de 2005 e foi colhida em dias alternados, armazenada em área coberta, e picada por meio de picadeira estacionária, imediatamente antes do fornecimento aos animais.

A silagem de milho foi confeccionada no Setor de Ovinocultura, em silo tipo trincheira com capacidade para 60 t. A variedade de milho utilizada na confecção da silagem foi a Tork, com densidade de 5 sementes/m linear, sendo as plantas colhidas aos 110 dias de idade, com grãos no ponto farináceo-duro. Os concentrados foram compostos por grão de milho triturado, farelo de soja, uréia, sal iodado, calcário calcítico, fosfato bicálcico e suplementos vitamínico e mineral, constituindo dietas isoproteicas e isoenergéticas.

As dietas foram calculadas de acordo com as exigências preconizadas pelo NRC (1985) para cordeiros desmamados com ganhos de peso estimados em $300 \mathrm{~g} / \mathrm{dia}$. Durante todo o período experimental, foram coletadas amostras dos ingredientes e das dietas para análise de sua composição química (Tabelas 1 e 2).

A composição percentual dos principais ácidos graxos dos volumosos e dos concentrados das dietas (Tabela 3) foi determinada conforme as metodologias de Maia \& Rodrigues-Amaya (1993) e ISO (1978), para metilação e transesterificação dos ácidos, respectivamente. 
Tabela 1 - Composição química dos ingredientes das dietas experimentais (expressas na matéria seca)

\begin{tabular}{|c|c|c|c|c|}
\hline Nutriente & Silagem de milho & Cana-de-açúcar & Farelo de soja & Milho moído \\
\hline Matéria seca (\%) & 29,30 & 26,48 & 88,34 & 86,96 \\
\hline Matéria orgânica (\%) & 25,51 & 24,35 & 81,60 & 84,71 \\
\hline Matéria mineral (\%) & 3,79 & 2,13 & 6,74 & 2,25 \\
\hline Proteína bruta (\%) & 8,67 & 2,92 & 49,06 & 8,95 \\
\hline Extrato etéreo (\%) & 3,02 & 0,43 & 1,86 & 3,87 \\
\hline Lignina (\%) & 2,90 & 3,66 & 2,40 & 2,15 \\
\hline Fibra em detergente neutro (\%) & 43,38 & 35,92 & 14,60 & 16,33 \\
\hline Fibra em detergente ácido (\%) & 22,48 & 20,52 & 10,20 & 3,93 \\
\hline Carboidratos totais $(\%)$ & 84,52 & 94,52 & 42,34 & 84,93 \\
\hline Carboidratos não-fibrosos (\%) & 41,14 & 58,60 & 25,84 & 63,32 \\
\hline
\end{tabular}

Tabela 2 - Composição das dietas experimentais (valores expressos na matéria seca)

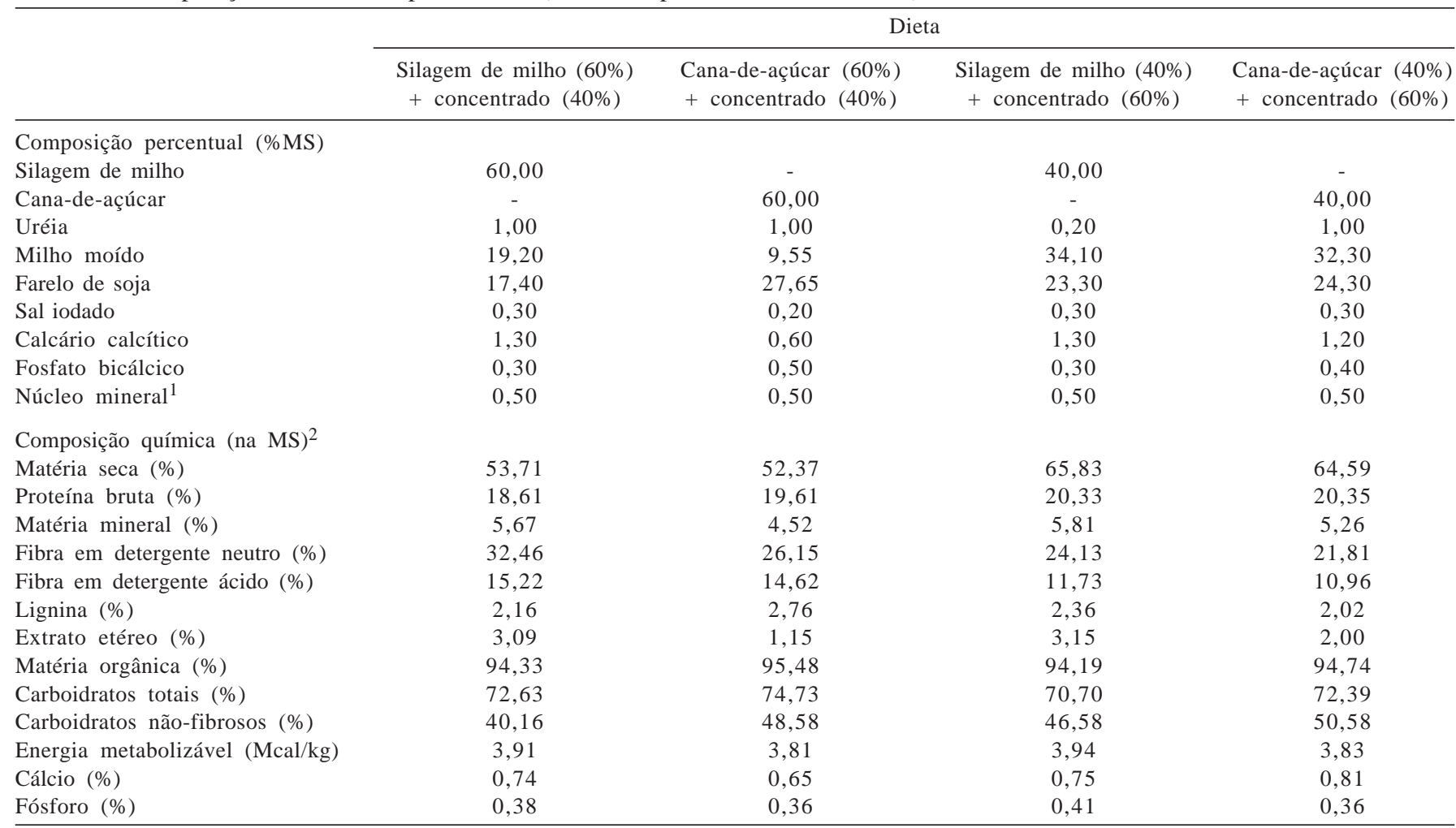

${ }_{1}^{1}$ Núcleo mineral: zinco - $1.600 \mathrm{mg}$; cobre - $300 \mathrm{mg}$; manganês - $1.500 \mathrm{mg}$; ferro - $1.100 \mathrm{mg}$; cobalto - $10 \mathrm{mg}$; iodo - $27 \mathrm{mg}$; selênio - $22 \mathrm{mg}$.

2 Análises realizadas no Laboratório de Nutrição Animal (LANA) da FCAV/Unesp.

Os animais foram alimentados diariamente às 7 e às $17 \mathrm{~h}$. As pesagens foram realizadas semanalmente e, quinzenalmente, avaliava-se o grau de infestação por helmintos, por meio da visualização da coloração da mucosa da conjuntiva dos animais (método Famacha ${ }^{\circledR}$ ), de acordo com Molento et al. (2004).

Ao atingirem $32 \mathrm{~kg}$ de peso corporal, os cordeiros foram mantidos em jejum de sólidos por 16 horas e, posteriormente, insensibilizados por eletronarcose ( $220 \mathrm{~V}$ por $10 \mathrm{~s}$ ), seguida de sangria, pela secção das veias jugulares e artérias carótidas. Após abate, esfola, evisceração e retirada da cabeça e dos membros, as carcaças foram resfriadas em câmara frigorífica a $4^{\circ} \mathrm{C}$ por 24 horas. Ao final desse período, foram divididas longitudinalmente em duas meiascarcaças.

Os lombos foram individualmente identificados, acondicionados em sacos plásticos de polietileno de baixa densidade $\left(0,910-0,930 \mathrm{~g} / \mathrm{cm}^{3}\right)$ e armazenados a $-18^{\circ} \mathrm{C}$ até o início das análises. No preparo das amostras para análises, os lombos foram descongelados dentro dos sacos plásticos, em geladeira a $10^{\circ} \mathrm{C}$ por 20 horas e, da porção medial do músculo longissimus lumborum, amostras foram retiradas e encaminhadas à liofilização (72 horas). Após a liofilização, calculou-se a umidade e determinou-se o conteúdo de cinzas, pela queima em mufla, e de proteína bruta, pelo método semi-micro Kjeldahl, conforme descrito por 
Tabela 3 - Composição percentual dos principais ácidos graxos dos volumosos e dos concentrados (expressa na matéria natural)

\begin{tabular}{|c|c|c|c|c|c|c|}
\hline \multirow[t]{2}{*}{ Ácido graxo } & \multicolumn{2}{|c|}{ Volumoso } & \multicolumn{4}{|c|}{ Concentrado } \\
\hline & Silagem de milho & Cana-de-açúcar & $\begin{array}{c}\text { Silagem } \\
\text { de milho (60\%) } \\
+ \text { concentrado } \\
(40 \%)\end{array}$ & $\begin{array}{c}\text { Cana-de- } \\
\text { açúcar }(60 \%) \\
+ \text { concentrado } \\
(40 \%)\end{array}$ & $\begin{array}{c}\text { Silagem } \\
\text { de milho }(40 \%) \\
+ \text { concentrado } \\
\\
(60 \%)\end{array}$ & $\begin{array}{c}\text { Cana-de- } \\
\text { açúcar }(40 \%) \\
+\quad \text { concentrado } \\
(60 \%)\end{array}$ \\
\hline C8:0 (caprílico) & - & - & 0,20 & 0,08 & 0,15 & 0,08 \\
\hline C12:0 (láurico) & 0,47 & 1,50 & - & - & - & - \\
\hline C17:0 (heptadecanoico) & - & - & 0,09 & 0,12 & 0,11 & 0,10 \\
\hline C18:0 (esteárico) & 3,96 & 8,08 & 3,76 & 3,50 & 3,20 & 3,10 \\
\hline C16:1 (palmitoleico) & 4,18 & - & 0,15 & 0,14 & 0,22 & 0,18 \\
\hline C18:1 19 (oleico) & 27,52 & 24,24 & 33,16 & 28,04 & 34,38 & 33,78 \\
\hline 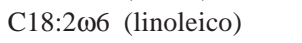 & 38,89 & 19,07 & 38,00 & 44,86 & 40,10 & 41,97 \\
\hline 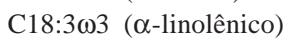 & 7,93 & 4,55 & 1,89 & 2,97 & 1,74 & 2,00 \\
\hline
\end{tabular}

Cunniff (1998). A extração de lipídios totais foi realizada utilizando-se a técnica a frio descrita por Folch et al. (1957), com solução de clorofórmio:metanol (2:1).

A quantidade de colesterol da carne foi determinada segundo metodologia de Bohac et al. (1988), adaptada por Bragagnolo \& Rodriguez-Amaya (2001), na qual 10 gramas de carne crua oriunda também da porção medial do músculo longissimus lumborum, foram submetidos à extração de lipídios com clorofórmio: metanol na relação 2:1. Em seguida, uma alíquota de $5 \mathrm{~mL}$ do extrato clorofórmico foi evaporada com nitrogênio gasoso e submetida à saponificação com solução de hidróxido de potássio em etanol a 12\%. A fração insaponificável (colesterol) foi extraída com hexano, purificada e submetida à reação de cor com ácido acético e ácido sulfúrico, tendo como catalisador o sulfato ferroso. Em seguida, foi procedida a leitura em espectrofotômetro a $490 \mathrm{~nm}$. A curva de calibração para colesterol foi elaborada utilizando-se $0,01 \mathrm{~g}$ de colesterol p.a. diluído em $50 \mathrm{~mL}$ de hexano, do qual foram retiradas alíquotas que corresponderam a 40, 80, 120, 160 e 200 mg/mL.

Para a transesterificação dos triacilgliceróis das amostras de carne crua, coletadas da porção medial do músculo longissimus lumborum, foi utilizado o método 5509 da ISO (1978), em solução de n-heptano e KOH/ metanol. Os ésteres de ácidos graxos foram isolados e analisados em cromatógrafo gasoso Shimadzu 14B, equipado com detector de ionização de chama e coluna capilar de sílica fundida (30 m de comprimento, 0,25 mm de diâmetro interno e $0,25 \mu \mathrm{m}$ de Omegawax 250). Os fluxos dos gases foram de 1,2 $\mathrm{mL} / \mathrm{min}$ para o gás de arraste $\left(\mathrm{H}_{2}\right) ; 30 \mathrm{~mL} / \mathrm{min}$

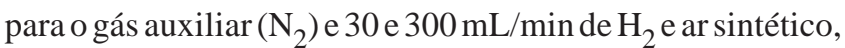
respectivamente. A temperatura inicial para a chama da coluna foi estabelecida em $50^{\circ} \mathrm{C}$, mantida por 2 minutos, sendo então elevada para $220^{\circ} \mathrm{C}$ a uma taxa de $4^{\circ} \mathrm{C} /$ minuto, permanecendo por mais 25 minutos. A razão de divisão da amostra foi de 1:100. As áreas dos picos foram determinadas por Integrador-Processador CG-300, e a identificação dos picos por comparação dos tempos de retenção com os padrões de ésteres metílicos de 37 ácidos graxos (Sigma ${ }^{\circ}$ cat. 189-19), abrangendo do C4:0 ao C24:1, cis - 15, no entanto sem o ácido linoleico conjugado (CLA).

O delineamento experimental foi o inteiramente casualizado em esquema fatorial $2 \times 2$ (duas relações volumoso:concentrado e dois volumosos), com quatro tratamentos e oito repetições. Os dados foram submetidos à análise de variância pelo procedimento GLM do pacote estatístico SAS (SAS, 1996) a 5\% de significância. Quando detectadas diferenças, as mesmas foram comparadas pelo teste Tukey no mesmo nível de significância. O modelo matemático utilizado foi:

$\mathrm{Y}_{\mathrm{ijk}}=\mu+\mathrm{R}_{\mathrm{i}}+\mathrm{V}_{\mathrm{j}}+\mathrm{RV}_{\mathrm{ij}}+\mathrm{e}_{\mathrm{ijk}}$, em que: $\mathrm{Y}_{\mathrm{ijk}}=$ valor observado da variável estudada no indivíduo k(1...8), recebendo a relação volumoso:concentrado i e volumoso j; $\mu$ = média geral; $\mathrm{R}_{\mathrm{i}}=$ efeito da relação volumoso:concentrado $i$, variando de 1 (60:40) a 2 (40:60); $\mathrm{V}_{\mathrm{j}}=$ efeito do volumoso $\mathrm{j}$, variando de 1 (silagem de milho) a 2 (cana-de-açúcar); $R V_{i j}=$ efeito da interação entre relação volumoso:concentrado e tipo de volumoso; $\mathrm{e}_{\mathrm{ijk}}=$ erro aleatório associado a cada observação.

\section{Resultados e Discussão}

Não houve efeito $(\mathrm{P}>0,05)$ da interação volumoso $\times$ relação volumoso:concentrado na composição centesimal e no teor de colesterol da carne dos cordeiros (Tabela 4). Independentemente das dietas, a umidade e os teores de proteína bruta, cinzas e colesterol do músculo longissimus lumborum não diferiram $(\mathrm{P}>0,05)$. $\mathrm{O}$ teor de extrato etéreo foi influenciado $(\mathrm{P}<0,05)$ pelo volumoso e pela relação volumoso:concentrado. 
Tabela 4 - Composicão centesimal e teor de colesterol do músculo longissimus lumborum de cordeiros terminados em confinamento com dietas contendo silagem de milho ou cana-de-açúcar em dois níveis de concentrado

\begin{tabular}{|c|c|c|c|c|c|}
\hline \multirow[t]{2}{*}{ Variável } & \multicolumn{2}{|c|}{ Volumoso } & \multicolumn{2}{|c|}{ Relação volumoso:concentrado } & \multirow[t]{2}{*}{ CV (\%) } \\
\hline & Silagem de milho & Cana-de-açúcar & $60: 40$ & $40: 60$ & \\
\hline Umidade (\%) & 74,30 & 74,79 & 74,28 & 74,81 & 0,81 \\
\hline Proteína bruta (\%) & 19,61 & 19,61 & 19,54 & 19,68 & 2,15 \\
\hline Extrato etéreo (\%) & $3,97 a$ & $3,71 b$ & $3,68 b$ & $4,02 \mathrm{a}$ & 3,30 \\
\hline Cinzas (\%) & 1,05 & 1,03 & 1,03 & 1,05 & 2,16 \\
\hline Colesterol (mg/100 g de carne) & 52,42 & 50,50 & 54,86 & 47,34 & 14,12 \\
\hline
\end{tabular}

Médias seguidas de letras distintas na linha diferem $(\mathrm{P}<0,05)$ entre si pelo teste Tukey.

CV = coeficiente de variação.

A carne dos cordeiros alimentados com a silagem de milho teve maior teor de extrato etéreo (3,97\%) se comparada à daqueles alimentados com as dietas contendo cana-deaçúcar (3,71\%) e isto pode ser atribuído às concentrações desse nutriente nas dietas, uma vez que a concentração de extrato etéreo das dietas contendo cana-de-açúcar foi inferior (1,58\%) à daquelas compostas de silagem de milho (3,12\%). Resposta semelhante foi obtida por Madruga et al. (2005), que estudaram a qualidade da carne de cordeiros Santa Inês terminados com $60 \%$ de volumoso e $40 \%$ de concentrado e verificaram menor teor de gordura (2,74\%) na carne dos animais terminados com dietas à base de palma forrageira em comparação à carne de animais terminados com silagem de milho (8,38\%).

A carne dos cordeiros que receberam dietas com mais concentrado teve maior teor de extrato etéreo (4,02\%) em comparação à dos alimentados com dietas contendo mais volumosos (3,68\%), realçando o maior teor de gordura na carne, em decorrência da alimentação mais concentrada. Esses valores de extrato etéreo foram inferiores aos obtidos por Rowe et al. (1999), em pesquisa na qual avaliaram o efeito de diferentes sistemas de terminação na composição centesimal da carne de cordeiros, com maior deposição de gordura (10,79\%) no músculo longissimus dorsi dos ovinos que receberam dieta rica em concentrado, em comparação aos 6,85\% de gordura da carne dos criados em pasto. Archimède et al. (2008), ao estudarem o efeito da inclusão de níveis crescentes de concentrado $(0,150,300$ e 600 g) nas dietas de cordeiros confinados, também observaram influência das mesmas sobre o teor de extrato etéreo da carne dos animais, o qual variou de 10,79 a 11,51\%.

Carson et al. (2001), ao investigarem o efeito de dietas com alta ou baixa relação volumoso:concentrado na terminação de cordeiros, não notaram diferenças na umidade e nos teores de proteína, gordura e cinzas na carne dos animais. Ao avaliar a carne de tourinhos terminados em confinamento com dietas contendo cana-de-açúcar (var. SP 80-1816) e dois teores de concentrado (40 e 60\%),
Fernandes et al. (2009a), também não observou diferenças na umidade e nos teores de proteína bruta, extrato etéreo e cinzas, com valores de 74,14; 22,85; 2,12 e 1,13\%, respectivamente.

A composição centesimal da carne dos cordeiros observada neste estudo, condiz com os valores observados por Prata (1999) para carne ovina, com $75 \%$ de umidade, 19\% de proteína, $4 \%$ de gordura e $1,1 \%$ de matéria mineral, podendo de acordo com Gurtler et al. (1987), ser considerada uma carne magra, por apresentar valores inferiores a 5\% de gordura.

O teor médio de colesterol obtido neste estudo foi inferior àqueles verificados por Rowe et al. (1999), que relataram teores de 62,03 e 57,76 mg/100g em carne de cordeiros terminados em pasto ou em confinamento, respectivamente e, superior ao observado por Russo et al. (1999), que também não verificaram influência das dietas com diferentes fontes energéticas nos teores de colesterol (48,33 mg/100 g de carne) dos músculos longissimus lumborum e semitendinosus. Madruga et al. (2005), encontraram 44,10 mg/100 g de colesterol na carne de cordeiros Santa Inês terminados com $60 \%$ de volumoso e $40 \%$ de concentrado.

Não houve efeito da interação volumoso $\times$ relação volumoso:concentrado e nem das dietas $(\mathrm{P}>0,05)$ para a maioria dos ácidos graxos (Tabela 5), para os totais dos ácidos saturados (AGS), insaturados (AGI), monoinsaturados (AGMI) e poliinsaturados (AGPI), e para as relações AGI:AGS, AGMI:AGS e GPI:AGS.

Os ácidos graxos encontrados em maior concentração foram os saturados mirístico (4,18\%), palmítico $(26,41 \%)$ e esteárico (17,09\%); o monoinsaturado oleico (37,93\%) e o poliinsaturado linoleico (4,00\%), constituindo $89,60 \%$ do total de ácidos graxos da carne dos cordeiros. A maior concentração desses ácidos graxos na carne ovina também foi verificada por Rowe et al. (1999), Madruga et al. (2005), Demirel et al. (2006) e Nuernberg et al. (2008), ao avaliarem o efeito de diferentes tipos de dietas na composição de ácidos graxos da carne de cordeiros. 
Tabela 5 - Perfil de ácidos graxos (\%) do músculo longissimus lumborum de cordeiros terminados em confinamento com dietas contendo silagem de milho ou cana-de-açúcar em dois níveis de concentrado

\begin{tabular}{|c|c|c|c|c|c|}
\hline \multirow[t]{2}{*}{ Ácido graxo } & \multicolumn{2}{|c|}{ Volumoso } & \multicolumn{2}{|c|}{ Relação volumoso:concentrado } & \multirow[t]{2}{*}{ CV (\%) } \\
\hline & Silagem de milho & Cana-de-açúcar & $60: 40$ & $40: 60$ & \\
\hline C8:0 (caprílico) & 0,85 & 0,84 & 0,84 & 0,85 & 41,61 \\
\hline C10:0 (cáprico) & $0,36 b$ & $0,47 \mathrm{a}$ & 0,43 & 0,39 & 15,38 \\
\hline C12:0 (láurico) & 0,60 & 0,46 & 0,60 & 0,46 & 32,91 \\
\hline C14:0 (mirístico) & 4,46 & 3,89 & 4,44 & 3,91 & 17,01 \\
\hline C15:0 (pentadecanoico) & $0,45 b$ & $0,58 \mathrm{a}$ & $0,57 a$ & $0,47 b$ & 10,16 \\
\hline C16:0 (palmítico) & 26,83 & 25,98 & 26,14 & 26,67 & 3,37 \\
\hline 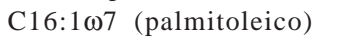 & $2,11 \mathrm{a}$ & $2,02 b$ & $2,16 a$ & $1,98 b$ & 2,43 \\
\hline C17:0 (heptadecanoico) & $0,96 b$ & $1,78 \mathrm{a}$ & $1,54 \mathrm{a}$ & $1,19 b$ & 13,56 \\
\hline C18:0 (esteárico) & 17,31 & 16,87 & 16,71 & 17,47 & 8,38 \\
\hline C18:1 199 (oleico) & 37,91 & 37,94 & 37,95 & 37,91 & 3,41 \\
\hline 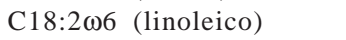 & 4,40 & 3,60 & 4,08 & 3,92 & 15,87 \\
\hline 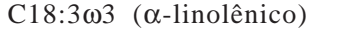 & $0,59 a$ & $0,25 b$ & 0,46 & 0,38 & 44,21 \\
\hline C20:2 (eicosadienoico) & $0,82 b$ & $1,16 a$ & 0,96 & 1,02 & 24,58 \\
\hline 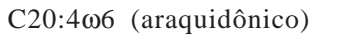 & $2,37 b$ & $4,17 \mathrm{a}$ & 3,13 & 3,41 & 14,28 \\
\hline AGS (saturados) & 51,81 & 50,86 & 51,27 & 51,40 & 2,51 \\
\hline AGI (insaturados) & 48,19 & 49,14 & 48,73 & 48,60 & 2,65 \\
\hline AGMI (monoinsaturados) & 40,02 & 39,97 & 40,10 & 39,89 & 3,24 \\
\hline AGPI (poliinsaturados) & 8,17 & 9,18 & 8,63 & 8,72 & 13,69 \\
\hline AGI:AGS & 0,93 & 0,97 & 0,95 & 0,95 & 4,99 \\
\hline AGMI:AGS & 0,77 & 0,79 & 0,78 & 0,78 & 4,99 \\
\hline AGPI:AGS & 0,16 & 0,18 & 0,17 & 0,17 & 15,18 \\
\hline
\end{tabular}

Médias seguidas de letras distintas na linha diferem $(\mathrm{P}<0,05)$ entre si pelo teste Tukey.

Os ácidos graxos saturados mirístico (C14:0) e palmítico (C16:0) são considerados hipercolesterêmios, porém, o esteárico (C18:0), que representa 10 a $20 \%$ das gorduras produzidas pelos ruminantes, não tem essa propriedade. Ao contrário dos saturados, que tendem a elevar os níveis de colesterol do sangue, os ácidos graxos mono e poliinsaturados são considerados hipocolesterêmios por serem efetivos na diminuição da concentração do mesmo (Williams, 2000; Valsta et al., 2005). Em razão dessas características, a carne dos cordeiros confinados com dietas contendo silagem de milho ou cana-de-açúcar IAC 86-2480, em dois níveis de concentrado, pode ser considerada um alimento saudável para o homem, haja vista suas baixas quantidades de C14:0 e C16:0 e alta de C18:1.

As quantidades dos ácidos graxos saturados (51,34\%), monoinsaturados $(40,00 \%)$ e poliinsaturados $(8,68 \%)$ indicam que a carne ovina é rica em ácidos graxos saturados e monoinsaturados, com menores quantidades de poliinsaturados, corroborando resultados obtidos por Monteiro et al. (2007). Entretanto, a relação AGPI:AGS na carne dos cordeiros deste trabalho $(0,17)$ ficou abaixo do valor ideal $(0,40)$, recomendado pelo Departamento de Saúde do Reino Unido para um alimento ser considerado saudável (Wood et al., 2003), uma vez que na carne de ruminantes esta relação geralmente é baixa, em torno de 0,1 (Scollan et al., 2001), variando de 0,06 a 0,15 em função do processo de biohidrogenação dos ácidos graxos poliisaturados no rúmen pela ação de microrganismos (French et al., 2000), com consequente formação de ácidos graxos saturados e monoinsaturados (Demeyer \& Doreau, 1999).

Fernandes et al. (2009a) estudaram a carne proveniente de tourinhos terminados em confinamento com dietas contendo cana-de-açúcar (var. SP 80-1816) e dois teores de concentrado (40 e 60\%) e não observaram diferenças ( $\mathrm{P}>0,05)$ entre as relações AGPI:AGS. Posteriormente, Fernandes et al. (2009b) analisaram a carne de bovinos da raça Canchim terminados em confinamento e observaram maior relação AGPI:AGS $(0,16)$ na dos animais que receberam cana-deaçúcar e concentrado acrescido de grãos de girassol em comparação à daqueles alimentados com silagem de milho e concentrado sem girassol $(0,11)$.

Ao considerar as concentrações dos ácidos graxos

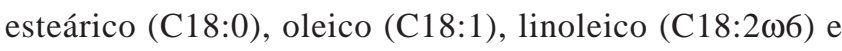

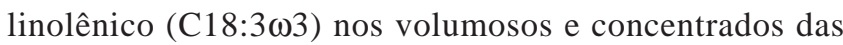
dietas (Tabela 3), bem como na carne dos cordeiros, notou-se redução no percentual dos poliinsaturados e aumento dos demais, confirmando a ocorrência de biohidrogenação. Demirel et al. (2006) avaliaram o efeito das relações volumoso:concentrado (75:25 e 25:75) no perfil de ácidos graxos da carne de cordeiros e verificaram que a carne dos animais alimentados com mais volumoso teve maior proporção dos ácidos oleico e esteárico em relação à dos alimentados com mais concentrado, sugerindo também maior biohidrogenação. 


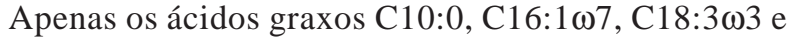
C20:4 $\omega 6$ foram influenciados pelas dietas $(\mathrm{P}<0,05)$ (Tabela 5 ) e, para os ácidos graxos C15:0, C17:0 e C20:2, houve efeito $(\mathrm{P}<0,05)$ da interação volumoso × relação volumoso: concentrado (Tabela 6).

As concentrações dos ácidos cáprico (C10:0),

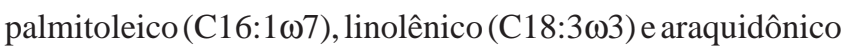
$(\mathrm{C} 20: 4 \omega 6)$ foram influenciadas $(\mathrm{P}<0,05)$ pelo tipo de

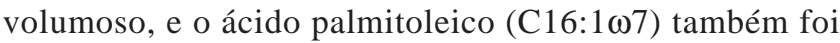
afetado $(\mathrm{P}<0,05)$ pela relação volumoso:concentrado. A carne dos cordeiros alimentados com dietas contendo canade-açúcar como volumoso teve maiores teores dos ácidos cáprico $(0,47)$ e araquidônico $(4,17)$, e menores dos ácidos palmitoleico $(2,02)$ e linolênico $(0,25)$ em comparação à dos alimentados com silagem de milho, cujos valores foram de 0,36 e 2,37 para os ácidos cáprico e araquidônico, e de 2,11 e 0,59 para os ácidos palmitoleico e linolênico. As dietas com maiores quantidades de volumoso (60:40) promoveram maior teor de palmitoleico $(2,16)$ na carne em comparação às dietas com mais concentrado (40:60), 1,98.

Na relação volumoso:concentrado 60:40, a carne dos cordeiros alimentados com cana-de-açúcar teve maior concentração do ácido graxo pentadecanoico em comparação à dos alimentados com silagem de milho. Quando o teor deste ácido graxo foi comparado entre as relações volumoso:concentrado, houve diferenças apenas entre as dietas contendo cana-de-açúcar, com maiores valores na relação 60:40 (Tabela 6).

As concentrações do ácido graxo heptadecanoico nas duas relações volumoso: concentrado foram maiores na carne dos cordeiros alimentados com cana-de-açúcar. Quando se comparou o teor deste ácido graxo entre as relações, houve também diferenças entre as dietas contendo cana-de-açúcar, com maior concentração na relação 60:40.

O ácido graxo eicosadienoico teve maior concentração na carne dos cordeiros alimentados com cana-de-açúcar quando comparados os volumosos em suas maiores proporções nas dietas. Quando comparadas as relações volumoso:concentrado, diferenças ocorreram apenas nas dietas contendo silagem de milho, com maior concentração deste ácido graxo na carne dos animais que receberam este volumoso em maiores quantidades.

Vale destacar que as maiores concentrações dos ácidos C15:0 e C17:0 observadas na carne dos cordeiros que receberam cana-de-açúcar em maiores proporções na dieta ocorreram em virtude do maior teor de sacarose da cana-deaçúcar, que propicia a produção de ácido propiônico no rúmen e favorece a formação dos ácidos graxos de cadeia ímpar pela síntes de novo (Fernandes et al., 2009b).

Tabela 6 - Desdobramento da interação volumoso × relação volumoso:concentrado para os ácidos graxos pentadecanoico (C15:0), heptadecanoico (C17:0) e eicosadienoico (C20:2) da carne de cordeiros terminados em confinamento com dietas à base de silagem de milho ou cana-de-açúcar e concentrado

\begin{tabular}{|c|c|c|c|c|}
\hline \multirow{2}{*}{\multicolumn{2}{|c|}{ Ácido graxo }} & \multirow[t]{2}{*}{ Volumoso } & \multicolumn{2}{|c|}{ Relação volumoso:concentrado } \\
\hline & & & $60: 40$ & $40: 60$ \\
\hline $\mathrm{C} 15: 0$ & (pentadecanoico) & $\begin{array}{l}\text { Silagem de milho } \\
\text { Cana-de-açúcar }\end{array}$ & $\begin{array}{l}0,46 \mathrm{Ab} \\
0,68 \mathrm{Aa}\end{array}$ & $\begin{array}{l}0,45 \mathrm{Aa} \\
0,48 \mathrm{Ba}\end{array}$ \\
\hline $\mathrm{C} 17: 0$ & (heptadecanoico) & $\begin{array}{l}\text { Silagem de milho } \\
\text { Cana-de-açúcar }\end{array}$ & $\begin{array}{l}0,95 \mathrm{Ab} \\
2,13 \mathrm{Aa}\end{array}$ & $\begin{array}{l}0,96 \mathrm{Ab} \\
1,42 \mathrm{Ba}\end{array}$ \\
\hline C20:2 & (eicosadienoico) & $\begin{array}{l}\text { Silagem de milho } \\
\text { Cana-de-açúcar }\end{array}$ & $\begin{array}{l}0,57 \mathrm{Bb} \\
1,34 \mathrm{Aa}\end{array}$ & $\begin{array}{l}1,06 \mathrm{Aa} \\
0,98 \mathrm{Aa}\end{array}$ \\
\hline
\end{tabular}

Médias seguidas pela mesma letra maiúscula na linha e mesma letra minúscula na coluna não diferem ( $\mathrm{P}>0,05)$ pelo teste Tukey.

\section{Conclusões}

Dietas contendo cana-de-açúcar e com maior quantidade de volumoso (60\%) promovem menor teor de gordura na carne de cordeiros. Em comparação à relação volumoso:concentrado das dietas, o tipo de volumoso exerce maior influência sobre o perfil de ácidos graxos da carne de cordeiros. Dietas contendo cana-de-açúcar em maiores proporções originam carne com maiores concentrações de ácidos graxos saturados de cadeia ímpar.

\section{Agradecimentos}

À Fundação de Amparo à Pesquisa do Estado de São Paulo (FAPESP), pelo apoio financeiro a esta pesquisa.

\section{Referências}

ARCHIMÈDE, H.; PELLONDE, P.; DESPOIS, P. et al. Growth performances and carcass traits of Ovin Martinik lambs fed various ratios of tropical forage to concentrate under intensive conditions. Small Ruminant Research, v.75, n.2-3, p.162-170, 2008. 
BOHAC, C.E.; RHEE, K.S.; ONO, K. Assessment of methodologies for colorimetric cholesterol assay of meats. Journal of Food Science, v.53, p.1642-1693, 1988.

BRAGAGNOLO, N.; RODRIGUEZ-AMAYA, D.B. Determinação de colesterol em carne: comparação de um método colorimétrico e um método por cromatografia líquida de alta eficiência. Revista do Instituto Adolfo Lutz, v.60, n.1, p.53-57, 2001.

CARSON, A.F.; MOSS, B.W.; DAWSON, L.E.R. et al. Effects of genotype and dietary forage to concentrate ratio during the finishing period on carcass characteristics and meat quality of lambs from hill sheep systems. Journal of Agricultural Science, v.137, n.2, p.205-220, 2001.

COSTA, R.G.; CARTAXO, F.Q.; SANTOS, N.M. et al. Carne caprina e ovina: composição lipídica e características sensoriais. Revista Brasileira de Saúde e Produção Animal, v.9, n.3, p.497-506, 2008.

CUNNIFF, P.A. Official methods of analyses of AOAC International. 16.ed. Arlington: Association of Official Analysis Chemistry, 1998. v.2. (CD-ROM).

DEMEYER, D.; DOREAU, M. Targets and procedures for altering ruminant meat and milk lipids. Proceedings of the Nutrition Society, v.58, n.3, p.593-607, 1999.

DEMIREL, G.; OZPINAR, H.; NAZLI, B. et al. Fatty acids of lamb meat from two breeds fed different forage: concentrate ratio. Meat Science, v.72, n.2, p.229-235, 2006.

FERNANDES, A.R.M.; SAMPAIO, A.A.M.; HENRIQUE, W. et al. Composição em ácidos graxos e qualidade da carne de tourinhos Nelore e Canchim alimentados com dietas à base de cana-de-açúcar e dois níveis de concentrado. Revista Brasileira de Zootecnia, v.38, n.2, p.328-337, 2009a.

FERNANDES, A.R.M.; SAMPAIO, A.A.M.; HENRIQUE, W. et al. Composição química e perfil de ácidos graxos da carne de bovinos de diferentes condições sexuais recebendo silagem de milho e concentrado ou cana-de-açúcar e concentrado contendo grãos de girassol. Revista Brasileira de Zootecnia, v.38, n.4, p.705-712, 2009b.

FOLCH, J.; LESS, M.; SLOANE, S.G.H. A simple method for the isolation and purification of total lipids from animal tissues. The Journal of Biological Chemistry, v.226, n.1, p.497509, 1957.

FRENCH, P.; STANTON, C.; LAWLESS, F. et al. Fatty acid composition, including conjugated linoleic acid of intramuscular fat from steers offered grazed grass, grass silage or concentrate based diets. Journal of Animal Science, v.78, n.5, p.2849-2855, 2000.

GURTLER, H.; KETZ, H.A.; SCHRODER, L. et al. Fisiologia Veterinária. Rio de Janeiro: Guanabara Koogan, 1987. 612p.

INTERNATIONAL ORGANIZATION FOR STANDARDIZATION - ISO. Animal and vegetable fats and oils - Preparation of methyl esters of fatty acids. Method ISO 5509, 1978. p.1-6.
MADRUGA, M.S.; SOUSA, W.H.; ROSALES, M.D. et al. Qualidade da carne de cordeiros Santa Inês terminados com diferentes dietas. Revista Brasileira de Zootecnia, v.34, n.1, p.309-315, 2005.

MAIA, E.L.; RODRIGUES-AMAYA, D. Avaliação de um método simples e econômico para metilação de ácidos graxos para lipídios de diversas espécies de peixes. Revista do Instituto Adolfo Lutz, v.53, n.1-2, p.27-35, 1993.

McAFEE, A.J.; McSORLEY, E.M.; CUSKELLY, G.J. et al. Red meat consumption: an overview of the risks and benefits. Meat Science, v.84, n.1, p.1-13, 2010.

MOLENTO, M.B.; TASCA, C.; GALLO, A. et al. Método Famacha como parâmetro clínico individual de infecção por Haemonchus contortus em pequenos ruminantes. Ciência Rural, v.34, n.4, p.1139-1145, 2004.

MONTEIRO, A.L.G.; FERNANDES, M.A.M.; BARROS, C.S. As pastagens e a qualidade da carne ovina para o consumo humano. Disponível em: <http://www.farmpoint.com.br>. Acesso em: 16/2/2007.

NATIONAL RESEARCH COUNCIL - NRC. Nutrient requirements of sheep. New York: National Academy Press, 1985. 99p.

NUERNBERG, K.; FISCHER, A.; NUERNBERG, G. et al. Meat quality and fatty acid composition of lipids in muscle and fatty tissue of Skudde lambs fed grass versus concentrate. Small Ruminant Research, v.74, n.1-3, p.279-283, 2008.

PRATA, L.F. Higiene e inspeção de carnes, pescado e derivados. Jaboticabal: FUNEP, 1999. 217p.

ROWE, A.; MACEDO, F.A.F.; VISENTAINER, J.V. et al. Muscle composition and fatty acid profile in lambs fattened in drylot or pasture. Meat Science, v.51, n.4, p.283-288, 1999.

RUSSO, C.; PREZIUSO, G.; CASAROSA, L. et al. Effect of diet energy source on the chemical-physical characteristics of meat and depot fat of lambs carcasses. Small Ruminant Research, v.33, p.77-85, 1999.

SCOLLAN, N.; CHOI, N.; KURT, E. et al. Manipulating the fatty acid composition of muscle and adipose tissue in beef cattle. British Journal of Nutrition, v.85, p.115-124, 2001.

SCOLLAN, N.; HOCQUETTE, J.F.; NUERNBERG, K. et al. Innovations in beef production systems that enhance the nutritional and health value of beef lipids and their relationship with meat quality. Meat Science, v.74, n.1, p.17-33, 2006.

STATISTICAL ANALYSIS SYSTEMS - SAS. User's guide. Cary: SAS Institute Inc., 1996. (CD-ROM).

VALSTA, L.M.; TAPANAINEN, H.; MÄNNISTÖ, S. Meat fats in nutrition. Meat Science, v.70, n.3, p.525-530, 2005.

VANDENDRIESSCHE, F. Meat products in the past, today and in the future. Meat Science, v.78, n.1-2, p.104-113, 2008.

WILliamS, C.M. Dietary fatty acids human health. Annales de Zootechnie, v.49, n.3, p.165-180, 2000.

WOOD, J.D.; RICHARDSON, R.I. ; NUTE, G.R. et al. Effects of fatty acids on meat quality: a review. Meat Science, v.66, n.1, p.21-32, 2003. 